\title{
Histamine: A Promoter of Xanthine Oxidase Activity in Intestinal Ischemia/Reperfusion
}

\author{
By M.G. Caty, D.J. Schmeling, H.P. Friedl, K.T. Oldham, K.S. Guice, and G.O. Till \\ Ann Arbor, Michigan and Hamburg, West Germany
}

\begin{abstract}
- Xanthine oxidase (XO)-derived oxygen radicals are thought to play an important role in the intestinal injury resulting from ischemia and reperfusion. In vitro data shows enhanced XO activity in the presence of histamine. Histamine is known to be released during intestinal ischemia and reperfusion. The purpose of this study was to evaluate the relationship between histamine and $X O$ in vivo in intestinal ischemia/reperfusion injury. Using an established model of gut ischemia and reperfusion, portal venous plasma was obtained and assayed for histamine levels, XO activity, and xanthine dehydrogenase $(X D)$ activity following injury. Intestinal ischemia for $\mathbf{1 2 0}$ minutes resulted in a $200 \%$ increase in plasma histamine levels $1263.4 \pm 36.9$ $\mathrm{nmol} / \mathrm{mL}$ control, $v 548.7 \pm 35.1 \mathrm{nmol} / \mathrm{mL}$ experimental, $P<.05)$. Reperfusion for 15 minutes resulted in a further increase in plasma histamine (to $658.3 \pm 33.9 \mathrm{nmol} / \mathrm{mL}$ ), compared with 120 minutes of ischemia alone. No significant change in plasma $X O$ activity resulted after simple ischemia for 120 minutes. However, XO activity doubled within 15 minutes of reperfusion of the ischemic intestine $\left(6.37 \pm 0.53 \mathrm{nmol} \mathrm{O}_{2}{ }^{-}\right.$per milliliter per minute $v 3.12 \pm 0.25$ nmol $\mathrm{O}_{2}{ }^{-}$per milliliter per minute, $P<.05$ ). Reperfusion for 60 minutes resulted in the maximal observed increase in plasma XO activity $\left(9.49 \pm 0.67 \mathrm{nmol} \mathrm{O}_{2}^{-}\right.$per milliliter per minute). Analysis of XD activity demonstrated no significant decrease compared with controls until 120 minutes of ischemia and 60 minutes of reperfusion $(1.62 \pm 0.49 \mathrm{nmol}$ uric acid per milliliter per minute at $\mathbf{6 0}$ minutes of reperfusion, versus $5.02 \pm 0.52 \mathbf{n m o l}$ uric acid per milliliter per minute control, $P<.05$ ). These data suggest that enhanced $X O$ activity due to calcium and protease-dependent conversion from XD results relatively late in the course of this ischemia/reperfusion injury, after the histamineassociated early increase in plasma $X O$ activity. In summary, intestinal ischemia followed by reperfusion results in parallel elevations of plasma histamine and XO activity. The early increase in XO activity is independent of conversion from XD but is temporally related to elevations in plasma histamine. These data suggest a role for histamine
\end{abstract}

From the Sections of Pediatric and General Surgery, Departments of Surgery and Pathology, University of Michigan Medical School, Ann Arbor, MI; and the Department of Trauma Surgery, University of Saarland Medical School, Hamburg, West Germany.

Supported in part by Grants No. HL38141, GM39397, and GM28499 from the National Institutes of Health, Bethesda, MD, and a grant (FR744-1) from the Deutsche Forschurigsgemeinschaft, Bonn, West Germany.

Presented at the 20th Annual Meeting of the American Pediatric Surgical Association, Baltimore, Maryland, May 28-31, 1989.

Address reprint requests to Keith T. Oldham, MD, University of Michigan, F7516 Mott Children's Hospital, Box 0245, Section of Pediatric Surgery, Ann Arbor, MI 48109-0245.

- 1990 by W.B. Saunders Company.

0022-3468/90/2502-0007\$03.00/0 as a pathogenic mediator of intestinal ischemia/reperfusion injury.

(6) 1990 by W.B. Saunders Company.

INDEX WORDS: Histamine; xanthine oxidase; intestinal ischemia; intestinal ischemia/reperfusion.

TNESTINAL ISCHEMIA followed by reperfusion is a frequent clinical event with important local and systemic consequences. Neonatal necrotizing enterocolitis, midgut volvulus, and nonocclusive mesenteric ischemia following resuscitation are all relevant clinical scenarios. The pathogenic mechanisms involved have been the focus of significant recent investigative efforts. This is related in part to the observations of Granger et al ${ }^{1}$ regarding the phlogistic role of oxygenderived free radicals in this setting. Subsequently it has become apparent that oxidant-induced tissue injury is one aspect of a complex series of cellular and humoral events linked to the endogenous inflammatory response. These events in turn appear to play a role in the pathogenesis of multiorgan system failure. ${ }^{2}$

Intestinal ischemic injury is thought to be initiated by interruption of intracellular, oxygen-dependent highenergy phosphate (adenosinetriphosphate [ATP]) production. The purine degradation products that result (Fig 1) include hypoxanthine. The net loss of cell charge is accompanied by increased cytosolic calcium, which is linked to the proteolytic conversion of xanthine dehydrogenase (XD) to xanthine oxidase (XO). ${ }^{3}$ Thus ischemia yields both a substrate (hypoxanthine) and an active enzyme (XO). When combined with molecular oxygen that is available as a result of reperfusion, the yield includes the superoxide anion $\left(\mathrm{O}_{2}{ }^{-}\right)$, which in turn serves to generate a variety of additional short-lived, toxic oxygen radical species $\left(\mathrm{H}_{2} \mathrm{O}_{2}, \mathrm{OH}, \mathrm{HOCl}\right.$, etc $)$.

This scenario is generally applicable to ischemia/ reperfusion events in many different target organs ${ }^{4,5}$; it was initially described in the cat intestine. ${ }^{6}$ Currently, there is abundant evidence and a consensus for a central role for $\mathrm{XO}$ in the pathogenesis of intestinal ischemia/reperfusion injury. ${ }^{1,6}$

Despite this agreement on a role for $\mathrm{XO}$, little is known about the control mechanisms that regulate its activity. Most investigators have focused on the events related to conversion of XD to XO late in the course of this injury. The purpose of this study was to investigate 


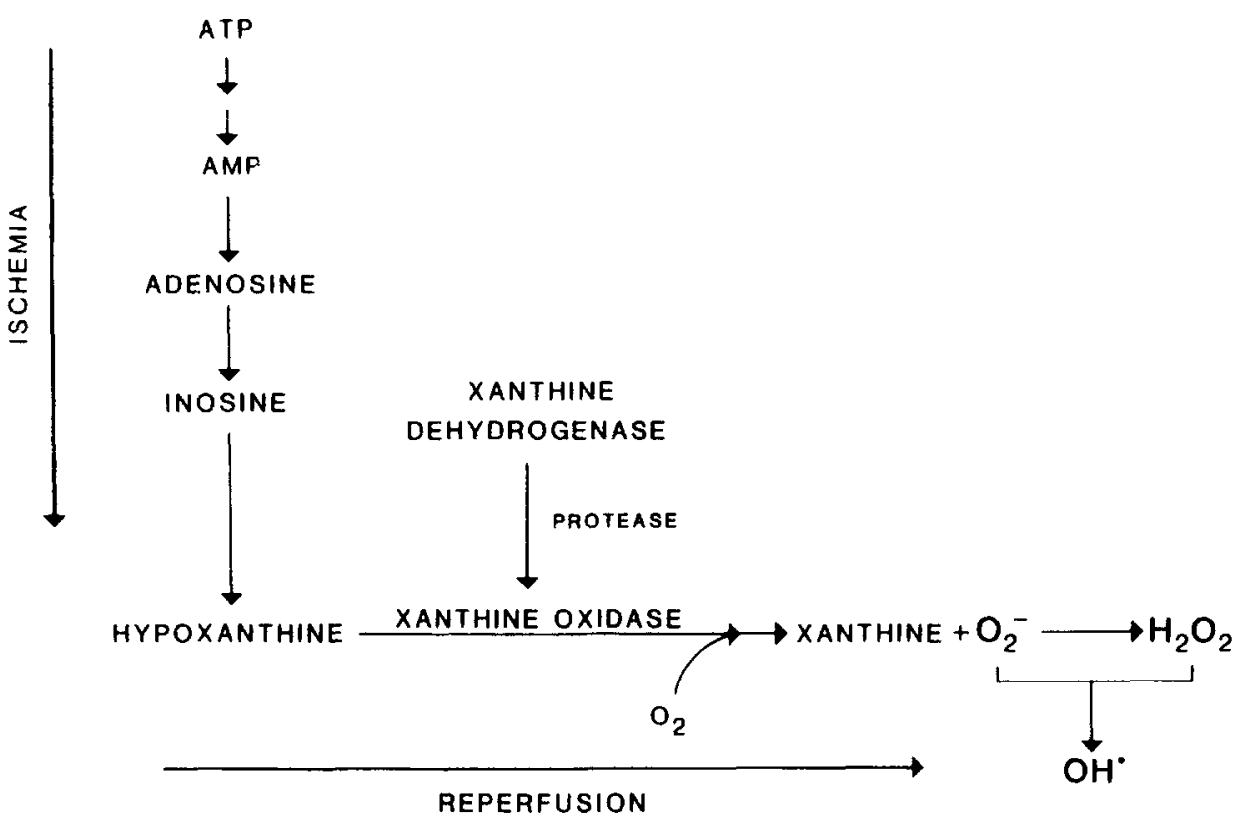

Fig 1. Purine degradation products resulting from ischemia provide the substrate for xanthine oxidase and molecular oxygen to generate oxygenderived free radicals. This ischemia/reperfusion scenario was proposed by Granger et $a 1^{6}$ in 1981.

a potential relationship between histamine and $\mathrm{XO}$ in a model of intestinal ischemia/reperfusion injury. This was based on observations we have made in other in vivo experimental models ${ }^{7}$ and on work by Muroka in $1963^{8,9}$ demonstrating in vitro that XO activity is enhanced by histamine.

\section{MATERIALS AND METHODS}

\section{Animal Model}

Pathogen-free male Sprague-Dawley rats (Charles River Laboratories, Portage, MI) weighing 100 to $150 \mathrm{~g}$ were used for all experiments. All experimental protocols were approved by the University of Michigan Committee on Use and Care of Animals and have been described previously. ${ }^{10}$ Following an overnight fast, animals were anesthetized by an intramuscular (IM) injection of ketamine hydrochloride $(100 \mathrm{mg} / \mathrm{kg})$.

Midline laparotomy was performed, the superior mesenteric artery isolated, and total mesenteric occlusion achieved by placement of a microvascular clip. Sham animals underwent similar preparation but did not have clip placement. Reperfusion of the ischemic intestine was achieved by removal of the microvascular clip during a second laparotomy. During the period of ischemia and reperfusion, animals remained hemodynamically stable. ${ }^{10}$ Once killed, portal venous blood samples were collected and diluted at a 1 to 1 ratio with a processing and storage medium containing potassium phosphate $(0.0024 \mathrm{~mol} / \mathrm{L}), \mathrm{NaCl}(0.15 \mathrm{~mol} / \mathrm{L})$ buffër, $\mathrm{pH}$ 7.35, dithiothreitol $(10 \mathrm{mmol} / \mathrm{L})$; phenylmethyl sulfonyl fluoride (1 $\mathrm{mmol} / \mathrm{L})$, and ethylenediaminotetraacetic acid $(10 \mathrm{mmol} / \mathrm{L})$. Following centrifugation at $4^{\circ} \mathrm{C}$, plasma samples were obtained for examination of histamine, $\mathrm{XO}$ activity, and $\mathrm{XD}$ activity.

\section{$X D / X O$ Activity}

$\mathrm{XO}$ activity assessed by superoxide anion generation in rat plasma was assayed spectrophotometrically (Gilford Response II, Gilford software V5.01 with advanced enzyme kinetics; Ciba Corning Diagnostics Corp, Oberlin, $\mathrm{OH}$ ) at $550 \mathrm{~nm}$, continuously monitoring the reduction of ferricytochrome $\mathrm{c}$ following addition of xanthine in the presence and absence of superoxide dismutase (SOD) at $37^{\circ} \mathrm{C}$. The reaction mixture contained $300 \mu \mathrm{L}$ ferricytochrome c (120 $\mu \mathrm{mol} / \mathrm{L}$ ), $200 \mu \mathrm{L} \mathrm{SOD} \mathrm{(500} \mathrm{U)} \mathrm{or} \mathrm{buffer} \mathrm{in} \mathrm{the} \mathrm{absence} \mathrm{of} \mathrm{SOD,} 200$ $\mu \mathrm{L}$ potassium phosphate $(0.0024 \mathrm{~mol} / \mathrm{L})$ and sodium chloride $(0.15$ $\mathrm{mol} / \mathrm{L}$ ) at $\mathrm{pH} 7.35$, and $200 \mu \mathrm{L}$ rat plasma. The reaction mixture was preincubated at $37^{\circ} \mathrm{C}$ for 3 minutes and subsequently started by addition of $100 \mu \mathrm{L}$ xanthine $(50 \mu \mathrm{mol} / \mathrm{L})$. The contents of the reference cuvette were the same except that plasma and xanthine were omitted. The amount of superoxide formed was calculated from the difference in optical density (OD) readings $( \pm$ SOD) after 10 minutes of reaction time using a molar extinction coefficient of 21.1 $\mathrm{cm}-1 \mathrm{mmol} / \mathrm{L}-1$ for cytochrome $\mathrm{c}$." $\mathrm{XO}$ activity was expressed as nmol $\mathrm{O}_{2}^{-}$formed per milliliter of plasma per minute. As expected, addition of allopurinol $(1 \mathrm{mmol} / \mathrm{L})$ or $\operatorname{SOD}(500 \mathrm{U})$ or omission of xanthine completely prevented the reduction of cytochrome $c$ (data not presented).

Uric acid formation. $\mathrm{XD}$ and $\mathrm{XO}$ activities were assayed by measurement of uric acid formation at $293 \mathrm{~nm}$ in the presence or absence of $\mathrm{NAD}^{+}$at $37^{\circ} \mathrm{C}$, as described by Waud and Rajagopalan. ${ }^{12}$ The reaction mixture contained $100 \mu \mathrm{L}$ xanthine $(50 \mu \mathrm{mol} / \mathrm{L}), 100$ $\mu \mathrm{L} \mathrm{NAD}{ }^{+}(500 \mu \mathrm{mol} / \mathrm{L})$ or buffer (in the absence of NAD $\left.{ }^{+}\right), 600$ $\mu \mathrm{L}$ potassium phosphate $(0.0024 \mathrm{~mol} / \mathrm{L})$ and sodium chloride $(0.15$ $\mathrm{mol} / \mathrm{L}$ ) at $\mathrm{pH} 7.35$, and $100 \mu \mathrm{L}$ rat plasma to a final plasma content of $5 \%(\mathrm{vol} / \mathrm{vol})$. Furthermore, as indicated, the reaction mixture contained $100 \mu \mathrm{L}$ of the uricase inhibitor 2,4 dihydroxy-6-carboxy1,3,5 triazine (oxonate) ${ }^{13}$ (Aldrich Chemical Co Inc, Milwaukee, WI) present in a final concentration of $3 \mu \mathrm{mol} / \mathrm{L}$. XO and XD activities were expressed as nanomoles of uric acid formed per milliliter of plasma per minute.

\section{Histamine-Radioimmunoassay}

To determine plasma histamine, a commercially available immunoassay kit from Amac Inc (Westbrook, ME) was used. This assay is based on the acylation of plasma histamine and its competition with $I^{125}$-acylated histamine for binding to a mouse monoclonal antibody. Results were calculated employing a standard curve from seven standard samples ranging between 0 and $150 \mathrm{nmol} / \mathrm{mL}$. Results were expressed as $\mathrm{nmol} / \mathrm{mL}$. 


\section{Statistics}

Data are expressed as mean \pm standard error of the mean. Significance between controls and experimental groups was determined using a two-way analysis of variance in combination with the Dunnett's multiple comparison test, with significance defined at $P<.05$.

\section{RESULTS}

\section{Histamine Levels After Intestinal Ischemial Reperfusion}

Intestinal ischemia followed by reperfusion resulted in significant release of histamine into portal vein plasma (Fig 2). Sham-operated animals had plasma histamine levels of $263.4 \pm 36.9 \mathrm{nmol} / \mathrm{mL}$. Intestinal ischemia of 120 minutes' duration resulted in a doubling in plasma portal venous histamine levels $(263.4 \pm$ $36.9 \mathrm{nmol} / \mathrm{mL} v 548.7 \pm 35.1 \mathrm{nmol} / \mathrm{mL}, P<.05)$. A further increase in plasma histamine levels occurred with 120 minutes of ischemia followed by 15 minutes of reperfusion $(658.3 \pm 33.9 \mathrm{nmol} / \mathrm{mL})$.

\section{XO Activity Levels After Intestinal Ischemia/Reperfusion}

$\mathrm{XO}$ activity was measured in the same plasma samples obtained for histamine levels (Fig 3). No significant increase in $\mathrm{XO}$ activity occurred after 120 minutes of ischemia alone $\left(3.71 \pm 0.26 \mathrm{nmol} \mathrm{O}_{2}^{-}\right.$per milliliter per minute $v 3.12 \pm 0.23 \mathrm{nmol} \mathrm{O}_{2}{ }^{-}$per milliliter per minute for control animals, $P>.05$ ). Reperfusion of the ischemic intestine for 15 minutes

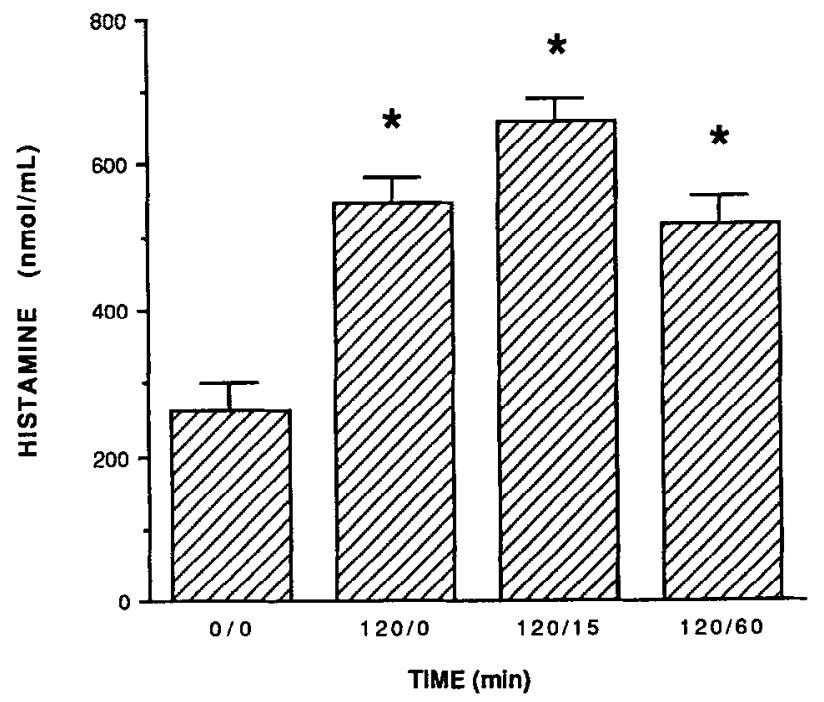

Fig 2. Portal venous plasma histamine levels during ischemia and reperfusion of the intestine. Time points on the $x$ axis represent minutes of ischemia per minutes of reperfusion; eg. 120/15 represents 120 minutes of ischemia and 15 minutes of reperfusion. $P<.05($.$) compared with sham-operated control$ animals using an analysis of variance in combination with Dunnett's multiple comparison test.

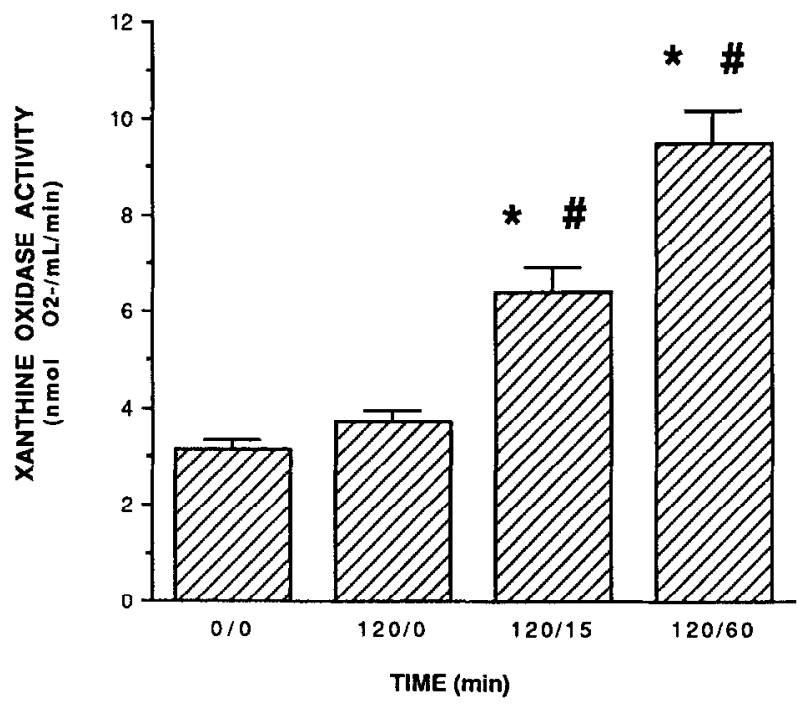

Fig 3. Plasma $X O$ activity during ischemia and reperfusion. $P<$ .05 compared with $0 / 0$ sham (.) and $120 / 0$ groups (\#) using an analysis of variance in combination with Dunnett's multiple comparison test. XO activity was unchanged with ischemia alone, but was significantly enhanced within 15 minutes of reperfusion.

resulted in a doubling of $\mathrm{XO}$ activity compared with control animals $\left(6.37 \pm 0.53 \mathrm{nmol} \mathrm{O}_{2}^{-}\right.$per milliliter per minute $v 3.12 \pm 0.23 \mathrm{nmol} \mathrm{O}_{2}^{-}$per milliliter per minute, $P<.05)$ and a $140 \%$ increase over animals subjected to 120 minutes of ischemia alone $(6.37 \pm 0.53$ nmol $\mathrm{O}_{2}^{-}$per milliliter per minute $v 3.71 \pm 0.26 \mathrm{nmol}$ $\mathrm{O}_{2}{ }^{-}$per milliliter per minute, $P<.05$ ). Reperfusion of the ischemic intestine for 60 minutes produced the highest levels of XO activity observed $(9.49 \pm 0.67$ nmol $\mathrm{O}_{2}^{-}$per milliliter per minute).

\section{XD Activity During Intestinal Ischemia/Reperfusion}

The proposed pathogenesis of intestinal ischemia/ reperfusion injury has assumed the conversion of XD to XO (Fig 1). In order to characterize the relationship between $\mathrm{XO}$ and histamine, XD activity was assessed at the same time points (Fig 4). Despite a trend toward decreasing plasma XD activity after 120 minutes of ischemia and 15 minutes of reperfusion, no significant decrease in activity occurred until 120 minutes of ischemia and 60 minutes of reperfusion $(1.62 \pm 0.49$ nmol uric acid per milliliter per minute $v 5.02 \pm 0.57$ nmol uric acid per milliliter per minute, $P<.05$ ).

\section{DISCUSSION}

Histamine is an abundant constituent of intestinal mast cells. ${ }^{14}$ Many stimuli are known to liberate histamine from mast cells. Among these stimuli are complement peptides, IgE, mechanical or thermal trauma, and oxygen radicals. ${ }^{15-17}$ Masini et al, ${ }^{18}$ using an isolated guinea pig heart, demonstrated a signifi- 


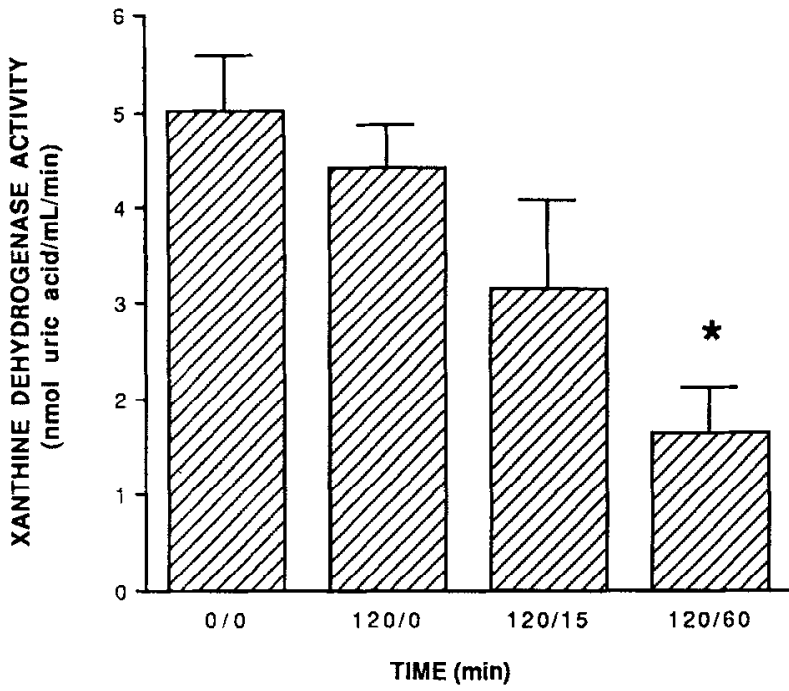

Fig 4. Plasma XD activity during intestinal ischemis and reperfusion. $P<.05$ (.) compared with sham animals using an analysis of variance in combination with Dunnett's test. Significant $X D$ conversion (to $X O$ ) did not occur until after 60 minutes of reperfusion. At 15 minutes of reperfusion, no significant XD to XO conversion had occurred despite the increase in XO shown in Fig 3.

cant release of histamine during myocardial reperfusion, which they attributed to oxygen radical-mediated exocytosis from mast cells.

A pathogenic role for histamine in intestinal ischemia and reperfusion has been suggested by Kusche et al. ${ }^{19,20}$ They demonstrated significant increases in mortality in animals given aminoguanethidine, a potent inhibitor of diamine oxidase (histaminase) during intestinal ischemia and reperfusion. Although the importance of histamine as a vasoactive substance was the emphasis of this study, the observation by Kusche et al has implications for our study of histamine-enhanced XO activity.

In this model, intestinal ischemia and reperfusion resulted in parallel elevations of plasma histamine and $\mathrm{XO}$ activity, the rise in histamine preceding $\mathrm{XO}$ temporally. An increase in XO activity at 120 minutes of ischemia and 15 minutes of reperfusion was independent of conversion from XD as there was no significant reduction in XD activity (Fig 4). By 120 minutes of ischemia and 60 minutes of reperfusion there was a significant conversion of XD to XO. A comparison of the total activity of XO plus XD is provided in Fig 5. A significant increase in the total (XO plus XD) activity occurred at 120 minutes of ischemia and 15 minutes of reperfusion, but XD activity was unchanged. Accordingly, the increase in combined (XO plus XD) total activity must result from an increase in XO activity independent of XD to XO conversion. As XD to XO conversion occurs by 60 minutes of reperfusion, the increase in XO activity at this time seems to result from conversion from XD. The earlier conversionindependent increase in plasma XO activity (at 120/ 15 ) that is associated with histamine elevations, parallels in vitro findings of histamine enhancement of XO activity. $^{7}$

The mechanism of histamine's effect on $\mathrm{XO}$ is unknown. Work by Till et $\mathrm{al}^{21}$ with a thermal injury model characterized by histamine release and increased $\mathrm{XO}$ activity has demonstrated no protective effect of $\mathrm{H}_{1}$ antagonists and only partial protection with $\mathrm{H}_{2}$ antagonists. Complete protection was afforded by cromolyn sodium, a mast cell stabilizer, ${ }^{7}$ and a potent inhibitor of histamine release. This would implicate a histamine receptor-independent effect of histamine on XO and suggests an allosteric enhancement of the enzyme by histamine. This concept remains speculative and awaits experimental confirmation.

We have demonstrated a temporal relationship between plasma histamine elevation and a (XD) conversion-independent increase in $\mathrm{XO}$ activity at early time points of intestinal ischemia and reperfusion. Later increases in XO activity resulted from the conversion from XD in this model and as others have suggested. This raises the possibility of a bimodal control of XO activity in intestinal ischemia/reperfusion and infers a pathogenic role for histamine in the injury. Pharmacologic therapy directed against histamine may have important effects on the injury resulting from intestinal ischemia and reperfusion.

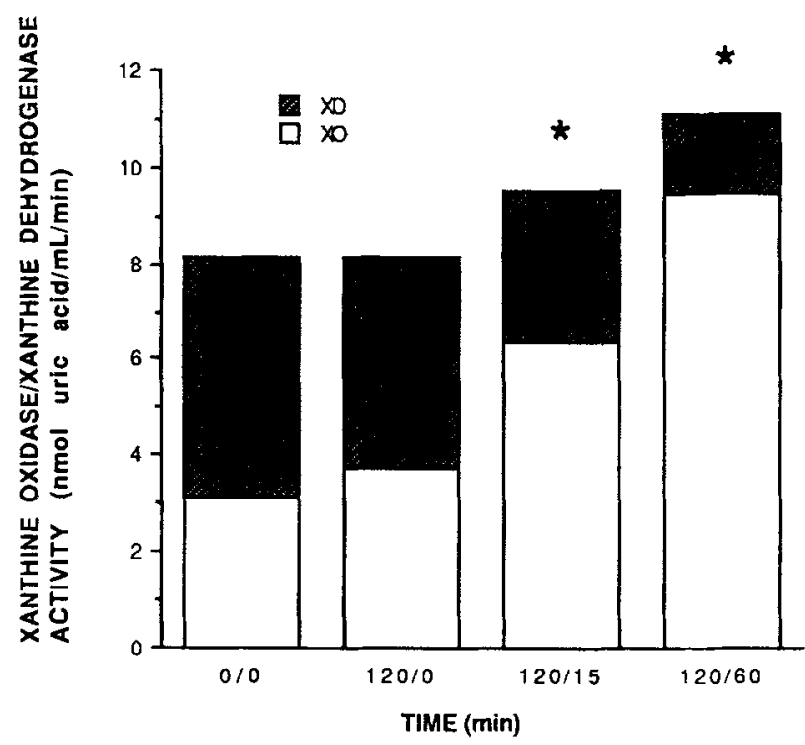

Fig 5. Total plasma $X O$ and $X D$ activity during intestinal ischemia and reperfusion. $P<.05(*)$ compared with sham animals using an analysis of variance in combination with Dunnett's test. Significant $X D$ to $X O$ conversion did not take place until 60 minutes of reperfusion had occurred, although a significant increase in XO activity occurred within 15 minutes of reperfusion. 


\section{REFERENCES}

1. Granger DN, McCord JM, Parks DA, et al: Xanthine oxidase inhibitors attenuate ischemia-induced vascular permeability changes in the cat intestine. Gastroenterology 90:80-84, 1986

2. Carrico CJ, Meakins JL, Marshall JC, et al: Multiple-organ failure syndrome. Arch Surg 121:196-208, 1986

3. Engerson TD, McKelvey TG, Rhyne DB, et al: Conversion of xanthine dehydrogenase to oxidase in ischemic rat tissue. J Clin Invest 79:1564-1570, 1987

4. Zweier JL, Rayburn BK, Flaherty JT, et al: Recombinant superoxide dismutase reduces oxygen free radical concentrations in reperfused myocardium. J Clin Invest 80:1728-1734, 1987

5. Korthuis RJ, Granger DN, Townsley MI, et al: The role of oxygen derived free radicals in ischemia-induced increases in canine muscle vascular permeability. Circ Res 57:599-609, 1985

6. Granger DN, Rutili G, McCord JM: Superoxide radicals in feline intestinal ischemia. Gastroenterology 81:22-29, 1981

7. Friedl HP, Till GO, Trentz O, et al: Roles of histamine, complement and xanthine oxidase in thermal injury of skin. Am J Pathol 135:203-217, 1989

8. Muroka S: Studies on xanthine oxidase: I. Activation of milk xanthine oxidase by histamine. Biochim Biophys Acta 73:17-26, 1963

9. Muroka S: Studies on xanthine oxidase: II. Mechanism of substrate inhibition and it's reversal by histamine. Biochim Biophys Acta 73:27-38, 1963

10. Schmeling DS, Caty MG, Oldham KT, et al: Evidence for a neutrophil-related acute lung injury following intestinal ischemiareperfusion. Surgery 106:195-202, 1989

11. McCord JM, Fridovich I: Superoxide dismutase: An enzymic function for erythrocuprein (Hemocuprein). J Biol Chem 244:60496055,1969
12. Waud WR, Rajagopalan KV: Purification and properties of the $\mathrm{NAD}^{+}$-dependent (Type $\mathrm{D}$ ) and $\mathrm{O}_{2}$-dependent (Type $\mathrm{O}$ ) forms of rat liver xanthine dehydrogenase. Arch Biochem Biophys 172:354-364, 1976

13. Hashimoto S: A new spectrophotometric assay method of xanthine oxidase in crude tissue homogenate. Anal Biochem 62:426435, 1974

14. Metcalfe DD: Mast cell mediators with emphasis on intestinal mast cells. Ann Allergy 53:563-575, 1984

15. Johnson AR, Hugli TE, Muller-Eberhard HJ: Release of histamine from mast cells by the complement peptides $\mathrm{C} 3 \mathrm{a}$ and $\mathrm{C} 5 \mathrm{a}$. Immunology 28:1067-1080, 1975

16. Kazimierczak W, Diamont B: Mechanisms of histamine release in anaphylactic and anaphylactoid reactions. Progr Allergy 24:295-365, 1978

17. Mannaioni PF, Masini E: The release of histamine by free radicals. Free Radic Biol Med 5:177-197, 1988

18. Masini E, Giannella E, Bianchi $\mathrm{S}$, et al: Histamine release in acute coronary occlusion-reperfusion in isolated guinea pig heart. Agents Actions 23:266-269, 1988

19. Kusche J, Lorenz W, Stahlknecht C-D, et al: Intestinal diamine oxidase and histamine release in rabbit mesenteric ischemia. Gastroenterology 80:980-987, 1981

20. Kusche J, Stahlknecht C-D, Lorenz W, et al: Comparison of alterations in the histamine-diamine oxidase system during acute intestinal ischemia in pigs, dogs, and rabbits: Evidence for a uniform pathophysiological mechanism? Agents Actions 9:49-52, 1979

21. Till GO, Guilds LS, Mahrougui M, et al: Role of xanthine oxidase in thermal injury of skin. Am J Pathol 135:195-202, 1989

\section{Discussion}

M. Clemens (Baltimore, MD): Your presentation has introduced us to a slightly different way of thinking about the free radical story, especially in intestinal ischemia. I have just a couple of questions, primarily with respect to compartmentalization. The $\mathrm{XO}$ and $\mathrm{XD}$ levels that you are reporting are plasma values, whereas we would think that the ones that would be most important for generating free radicals to cause tissue injury would be tissue $\mathrm{XO}$. Have you measured any tissue values of the increase in the $\mathrm{XO}$ activity, and also when you reported that by blocking the histamine production you decrease the amount of plasma XO activity, did this result in an improvement in tissue function or an amelioration of tissue injury during reperfusion?

W. Andrews (Dallas, $T X$ ): In our hands we have been looking at mesenteric occlusion in rats and looking at survivability. We found that at 60 minutes of occlusion there is about $80 \%$ mortality, and with 90 minutes of occlusion $100 \%$ mortality results with severe bowel necrosis. You have used 120 minutes of intestinal ischemia. Have you done any of these studies in some lower time periods of occlusion? Is there a dose- or time-response curve to histamine release, or is this seen only at a very severe level of ischemia?

$P$. Cherko (Philadelphia, $P A$ ): Have your correlated your increased levels of $\mathrm{XO}$ activity due to histamine enhancement with histologic sections?

M.G. Caty (response): Dr Clemens, in other experimental models we have demonstrated that a rise in plasma $\mathrm{XO}$ activity correlates with a rise in tissue XO activity. In this experiment, we measured plasma $X O$ and $X D$ to allow a more direct comparison with plasma histamine activity. When we used cromolyn sodium in animals subjected to intestinal ischemia and reperfusion, there was a decrease in plasma histamine and a concomitant decrease in plasma $\mathrm{XO}$ activity. In addition, there was protection against oxidant-mediated tissue injury as measured by lipid peroxidation products. At the early time points, 120 minutes of ischemia and 15 minutes of reperfusion, there was a reduction in lipid peroxidation products as well as preservation of tissue adenosine triphosphate when cromolyn sodium was used. At the later time points, the protection was 
not apparent but that would be expected since there was XD-to-XO conversion by that time, and presumably the histamine effect would no longer be important.

Dr Andrews, in a series of in vitro experiments we have demonstrated that histamine's effect on XO activity is concentration-dependent. In earlier in vivo experiments, we looked at 60 minutes of intestinal ischemia, and found that histamine levels in the portal venous blood did not reach the in vitro threshold level necessary to induce an increase in XO activity. With respect to survivability, we found that animals sub- jected to 60 minutes of intestinal ischemia had a mortality rate of approximately $50 \%$ to $60 \%$ at 24 hours. These data are from a much earlier time point. In our model, 120 minutes of ischemia yields a predictably lethal injury.

Dr Cherko, we have found, as I showed on the electronmicrographs, that when we gave cromolyn sodium to animals subjected to intestinal ischemia, mast cell degranulation was prevented and normal cellular architecture was better preserved. We have not done this analysis in a quantitative way. 